\title{
Awareness during anaesthesia
}

The introduction of muscle relaxants was associated with an increased incidence of expressed fears about paralysis during surgery without absence of pain. Some anaesthetics tended to disregard these claims and even to assert that awareness could not happen under properly conducted general anaesthesia.

The signs of awareness, which may be those of light anaesthesia (tachycardia, hypertension, mydriasis, lacrimation) are neither pathognomic nor always present. Esoteric apparatus and investigations have not yet resulted in a kit which, when attached to a patient, indicates "I am asleep."

Awareness may be explicable or inexplicable. The diagnosis of awareness involves memory and detailed recollection by a patient after operation of independently verifiable random events during operation. This does not often occur but when it does it is a catastrophic event for both patient and anaesthetist. The various causes have been noted, reviewed and ignored before. ${ }^{1-6}$

There are a few circumstances in which anaesthesia is intentionally cconomical in the interests either of patient survival or, more commonly, in the (mistaken) view that light general anaesthesia for Caesarean section, for example, is safer for the neonate. Both the moribund patient and the mother can, however, be informed of the likelihood of awareness under specified circumstances, arrangements made for them to signal to the observer their comfort or discomfort, and by this means subsequent problems averted. 7.8

Reports of awareness which are more difficult to explain are those which follow apparently uneventful and conventional general anaesthesia. It is relatively rare, but clear memory, usually without complaint of pain, of events which at best are similar to known occurrences, are recalled.

Levinson ${ }^{9}$ reported 20 years ago that, with the use of hypnosis, in an unrepeatable study, some patients could be induced to recall operative events. Other workers, ${ }^{10}$ particularly psychologists, have attempted ethical studies which, in general, corroborate these alarming findings. The degree of importance which should be attached to the observations is, at the moment, unsure. The incidence, outside the sample populations of investigations, is unknown. The relevonce is also unknown: the fact that an event can be recalled under hypnosis, but not recollected in normal consciousness, may or may not be important, and the degree of harm thus caused is probably not measurable.

One of the confounding variables in studies of this phenomenon is the occurrence of dreams. The estimates of incidence of dreaming vary, not only with observers but also with drugs. ${ }^{11-14}$ The problem of recall is also a source of confusion: not everyone has similar ability to remember events particularly if these were, or might have been dreamt. ${ }^{15}$ Is it possible that events which cannot be recollected have harmful effects?

Recent independent research ${ }^{16-18}$ i.rs again confirmed that auditory input during general anaesthesia is possible and that sometimes it can be recalled subsequently. The importance, relevance, or salience ${ }^{19}$ to the individual is a useful stimulus and evidence about this has been adduced. Salience for the individual cannot be predicted. ${ }^{20}$

Benign, neutral, messages can be recalled by some individuals: the possibility that positive, therapeutic, beneficial suggestions might be made during general anaesthesia should not be dismissed.

The medicolegal implications of these discoveries also cannot be ignored. Explicable awareness can often not be defended: this is particularly the case if any semblance of a guarantee of unconsciousness has been given to a patient by the anaesthetist. If, on the other hand, a patient has been warned (and a contemporaneous record made) that awareness is a possibility then a defence, in the event of complaint, is at least possible. Inexplicable awareness has to result in harm before claims of negligence are likely to succeed.

The avoidance of explicable awareness is merely the good practice of anaesthesia. Accidents, by definition, can probably not always be avoided. Inexplicable awareness may never be eradicated because its incidence is probably described by one extreme of the normal distribution curve of biological variation of response to drugs.

Department of Anaesthetics, University of Wales College of Medicine, Heath Park, Cardiff, CF4 4XN. 


\section{References}

1 Hutchinson $R$. Awareness during surgery. Br J Anaesth 1960; 33: 463-9.

2 Waters $J$. Factors causing awareness during surgery. Br J Anaesth 1968; 40: 259-64.

3 Breckenridge $J L$. Ailkenhead AR. Awareness during anaesthesia. A review. Annals of the Royal College of Surgeons of England 1983; 65: 93-6.

4 Jones JG, Konieczko K. Hearing and memory in anaesthetized paticnts. Br Med J 1986; 292: 1291-3.

5 Editorial. The depth of anaesthesia. Lancet $1986 ; 2$ : $553-4$.

6 Editorial. Advertising during anacsthesia. Lancet 1986; 2 : 1019-20.

7 Tunstall ME. Detecting wakefulness during general anaesthesia for Caesarean section. Br Med J 1977; 1: 1321.

8 Tunstall ME. The reduction of amnesia wakefulness during Caesarean section. Anaesthesia 1979; 34: 316-9.

9 Levinson $B W$. States of awareness during general anaesthesia. Br J Ansesth 1965; 37: 544-6.

10 Cheek $D B$. Unconscious perception of meaningful sounds during surgical anesthesia as revealed under hypnosis. Am J Hyp 1964; 6: 237-40.

11 Utting JE. In: Recent advances in anaesthesia and analgesia. Atkinson RS \& Hewer CL (Eds). Edinburgh. Churchill. 1982.

12 Wilson SL, Vaughan $R W$, Stephen $C R$. Awareness, dreams, and hallucinations associated with general anesthesia. Anesth Analg 1975; 54: 609-17.

13 Farnsworth GM. Enflurane and the incidence of awareness in Caesarean section. Anaesthesia 1978; 33: 553.

14 Harris TJB, Brice DD, Hetherington RR, Utting JE. Dreaming associated with anaesthesia: the influence of morphine. Br J Anaesth 1971; 43: 172-8.

15 Cohen $D$. Remembering and forgetting dreams. In: Functional disorders of memory. Kihlstrom JF, Evans FJ (Eds). 239-74 Wilcy, London 1979.

16 Goldmann L, Shah MV, Hebden M. Memory of cardiac anaesthesia. Anaesthesia 1987; 42 : In Press.

17 Bonke B, Schmitz PIM, Verhage F, Zwaveling A. Clinical study of so-called unconscious perception during gencral anaesthesia. Br J Anaesth 1986; 58: 957-64.

18 Bennett HL, Davis HS, Giannini JA. Non verbal response to intraoperative conversation. Br J Anaesth $1985 ; 57$ : $174-9$.

19 Goldmann L. Awareness under general anaesthesia. $\mathrm{PhD}$ thesis. University of Cambridge, 1986.

20 Goldmann $L$, Levey $A B$. Orienting under anaesthesia (Letter). Anaesthesia 1986; 41: 1056-7. 